\title{
Seasonal Variation of the Aerosol Light Scattering Coefficient in Marine Air of the Northeast Atlantic
}

\author{
Aditya Vaishya, S. G. Jennings, and Colin O’Dowd \\ School of Physics and Centre for Climate and Air Pollution Studies, Ryan Institute, National University of \\ Ireland, Galway, Galway, Ireland \\ Correspondence should be addressed to Aditya Vaishya, a.vaishya1@nuigalway.ie \\ Received 6 June 2011; Accepted 15 August 2011 \\ Academic Editor: Harry D. Kambezidis
}

Copyright ( 92011 Aditya Vaishya et al. This is an open access article distributed under the Creative Commons Attribution License, which permits unrestricted use, distribution, and reproduction in any medium, provided the original work is properly cited.

Aerosol light scattering measurements were carried out using a TSI 3563 Nephelometer at the Mace Head Atmospheric Research Station, on the west coast of Ireland from year 2001-2010. A strong seasonal trend in the aerosol light scattering coefficient at $550 \mathrm{~nm}\left(\sigma_{\text {scat }}\right)$, for clean marine air masses, is observed with a high $\sigma_{\text {scat }}$ value, [average (geometric mean)] of $35.3 \mathrm{Mm}^{-1}$ $\left(29.5 \mathrm{Mm}^{-1}\right)$, in January and a low $\sigma_{\text {scat }}$ value of $13.7 \mathrm{Mm}^{-1}\left(10.2 \mathrm{Mm}^{-1}\right)$, in July. This near threefold increase in the $\sigma_{\text {scat }}$ value during the winter season is because of the large contribution of wind-speed generated sea-salt particles in the marine boundary layer. A high positive correlation coefficient of 0.82 was found between the percentage occurrence of relatively large Ångström exponent $(\AA)$ values $(>1.2)$ and the percentage occurrence of lower $\sigma_{\text {scat }}$ values $\left(5-15 \mathrm{Mm}^{-1}\right)$ in the summer season. $\sigma_{\text {scat }}$ and wind-speed have a high positive correlation coefficient of 0.88 whereas $\AA$ and wind-speed have a negative correlation coefficient of -0.89 . $\AA$ values during the summer months indicate the dominance of sub- $\mu \mathrm{m}$ particles thus indicating the contribution of non-sea-salt sulphate and organics towards the $\sigma_{\text {scat }}$ as these species show an enhanced concentration during the summer months.

\section{Introduction}

Knowledge of the light scattering properties of atmospheric aerosol particles is of vital importance in estimating the radiative forcing of climate and in global radiation budget studies. Uncertainties in the global aerosol direct and indirect effects are nearly the same or twice as much as the magnitude of the effect itself as estimated by the Intergovernmental Panel on Climate Change (IPCC) in its 4th assessment report [1]. Several-long term measurements of key aerosol properties (e.g., aerosol light scattering and aerosol light absorption coefficient, condensation nuclei number concentration, etc.) at various measurement stations across the globe, for example [2-6], have been reported. Such longterm measurements of key aerosol properties at worldwide locations will be effective in reducing the uncertainties associated with aerosol direct and indirect effects.

The aerosol light scattering coefficient, an extensive optical property, can yield crucial information about the aerosol size distribution and composition if its wavelength dependence from which the Ångström exponent-an intensive optical property (independent of particle number concentration) is derived [7]. In the marine environment, the main constituent of aerosol particles is wind speed-generated sea salt $[8,9]$. Non-sea salt (nss) sulphate and organics also can dominate the sub- $\mu \mathrm{m}$ mass fraction depending upon the season and air mass history [10-12] as in the case of the Mace Head Atmospheric Research Station [13] on the west coast of Ireland.

We report here seasonal trends and analysis of a decadelong aerosol scattering database starting from 2001. In particular, impact of seasonal trends of sub- $\mu \mathrm{m}$ and super$\mu \mathrm{m}$ particles on $\sigma_{\text {scat }}$ for clean marine air masses is reported. Annual cycle of monthly averages of $\sigma_{\text {scat }}$ and $\AA$ is examined with respect to annual cycle of monthly average of wind speed.

\section{Measurements}

Aerosol light scattering properties were measured from 2001 to 2010, at the Mace Head Atmospheric Research Station, on 
the northeast edge of the Atlantic Ocean. The Mace Head coastal Research Station $\left(53^{\circ} 19^{\prime} \mathrm{N}, 9^{\circ} 54^{\prime} \mathrm{W}\right)$ on the periphery of Western Europe is an important Global Atmosphere Watch (GAW) measurement site and is designated as a clean marine background station for atmospheric aerosol research. Its unique location on the north-east edge of the Atlantic Ocean enables it to receive air masses of different origin and hence different aerosol types [14]. Air masses arriving at the site are from the designated clean marine sector of $180^{\circ}-300^{\circ}$ [15] nearly $52 \%$ of the time throughout the year. The spring to autumn season is characterized by, high biological activity (HBA) period in the North Atlantic Ocean in contrast to low biological activity (LBA) during the winter season. During HBA periods, organic matter contributes about $63 \%$ to the sub- $\mu \mathrm{m}$ aerosol mass in contrast to $15 \%$ during LBA periods [10]. Yoon et al. [11] reported similar seasonal variations in the mass concentration of sea salt, nss sulphate, water-soluble organic carbon (WSOC), and total carbon (TC). While sea salt mass concentration showed maxima in the winter season and minima in the summer season, nss sulphate mass concentration in fine mode exhibited an opposite trend. Mulcahy et al. [16] reported that for clean marine sector air masses over the North Atlantic Ocean, a high correlation coefficient of 0.97 between aerosol optical depth (AOD) and the square of wind speed exists, thus confirming the contribution of sea-spray-generated aerosols to enhanced $\sigma_{\text {scat }}$ values during the winter season.

Aerosol light scattering measurement were carried out at the Mace Head research station using a three-wavelength $(450,550$, and $700 \mathrm{~nm})$ nephelometer (TSI 3563) instrument. Anderson et al. [17] have described in detail the performance characteristics of this commercially available instrument and Anderson and Ogren [18] have thoroughly discussed the calibration approach for optimal performance. Due to its closed chamber design, high sensitivity, relatively simple calibration technique, and easily replaceable components it is suitable for long-term air quality monitoring. A detailed review of design philosophy and possible applications of the integrating nephelometer is presented by Heintzenberg and Charlson [19]. At Mace Head, the Nephelometer instrument is connected to a community airsampling system via a $25 \mathrm{~mm}$ diameter stainless tube. The flow through the $100 \mathrm{~mm}$ duct was maintained at 150 LPM. At this high flow rate, aerosol losses may occur in the sampling system thus introducing discrepancies between modeled and measured $\sigma_{\text {scat }}$ values [20]. Kleefeld et al. [20] reported the $50 \%$ cutoff diameter of the inlet system to be about $8 \mu \mathrm{m}$ at wind speeds less than $5 \mathrm{~ms}^{-1}$ and this cutoff diameter reduces to $4 \mu \mathrm{m}$ at a wind speed of $10 \mathrm{~ms}^{-1}$. In the present case the mean wind speed for the 10 -year period was $7 \pm 4 \mathrm{~ms}^{-1}$. Also the 75 th percentile of the mean wind speed value was below $10 \mathrm{~ms}^{-1}$, and the 95 th percentile of the mean wind speed value was below $14 \mathrm{~ms}^{-1}$. Hence a size cutoff of $4 \mu \mathrm{m}$ or above is considered to be appropriate in the present case.

The following criteria were applied to ensure the data quality and to qualify the scattering coefficient data to be under clean sector conditions.
(1) Hourly averaged black carbon mass concentration $\leq 50 \mathrm{ng} / \mathrm{m}^{3}$.

(2) Hourly averaged wind direction between $190^{\circ}$ and $300^{\circ}$.

(3) All the raw data with frequency less than 1 hour were averaged into hourly data if at least $66 \%$ of the measurements during that hour were available.

Black carbon mass concentration values used in this study were obtained from two different aethalometers [21, 22] models: AE-9 from 2001 up to April 2005 and AE-16 from May, 2005 up to 2010. The clean sector criteria (1 and 2) mentioned above are based on previous studies of North-East Atlantic marine air masses [15, 23]. The yearly average ambient relative humidity $(\mathrm{RH})$ at the Mace Head research station is $84 \pm 10 \%$ which is higher than the deliquescence $\mathrm{RH}$ of $\left(\mathrm{NH}_{4}\right)_{2} \mathrm{SO}_{4}$ and $\mathrm{NaCl}$. Both $\left(\mathrm{NH}_{4}\right)_{2} \mathrm{SO}_{4}$ and $\mathrm{NaCl}$ are known to be highly hygroscopic $[24,25]$ and in their deliquescence state they significantly enhance the $\sigma_{\text {scat }}[24,26]$. Fierz-Schmidhauser et al. [27] reported a light scattering enhancement factor, the ratio of scattering at high $(85 \%)$ and low $(<40 \%) \mathrm{RH}, f(\mathrm{RH})=\sigma_{\text {scat }}(\mathrm{RH}) / \sigma_{\text {scat }}($ dry $)$, of $2.22 \pm 0.17$ for clean marine air masses during the winter season at Mace Head. In the present case, though the ambient average $\mathrm{RH}$ is $84 \pm 10 \%$, the light scattering measurements are still representative of dry scattering coefficient as the average $\mathrm{RH}$ within the Nephelometer measurement chamber remained around $34 \pm 8 \%$ because of the heating caused by the instrument lamp.

\section{Results and Discussion}

The clean sector $\sigma_{\text {scat }}$ at the Mace Head Atmospheric Research Station has a distinctive seasonal cycle with high scattering values in the winter season as compared to the summer season, as shown in Figure 1. The month of January has the highest $\sigma_{\text {scat }}$ value (average (geometric mean)) of 35.3 $\mathrm{Mm}^{-1}\left(29.5 \mathrm{Mm}^{-1}\right)$ and the month of July has lowest $\sigma_{\text {scat }}$ value of $13.7 \mathrm{Mm}^{-1}\left(10.2 \mathrm{Mm}^{-1}\right)$. The gradual decrease of scattering from January to July-August and a gradual increase from there on is directly correlated with the higher contribution of wind speed-generated sea salt particles in the marine boundary layer during winter time $[11,28]$. The $\sigma_{\text {scat }}$ values reported by Yoon et al. [11], $21 \mathrm{Mm}^{-1}$ in February and $5.5 \mathrm{Mm}^{-1}$ in August, are lower than the values reported in this study. They considered 48 cases over a 30 -month period from January, 2002 to June, 2004. The apparent difference in the $\sigma_{\text {scat }}$ values may be due to more stringent wind speed conditions laid down by Yoon et al. [11] on the scattering data, where they removed the days of scattering when wind speeds were abnormally high or low. Removal of scattering values corresponding to abnormal high wind speed episodes probably reduced the impact of sea salt on the light scattering during the winter months. In addition to this, they also excluded the days of scattering in summer when wind speeds were abnormally high. This criteria was imposed on the scattering data by Yoon et al. [11] in order to study the effects of organics and sulphates on aerosol scattering, which 


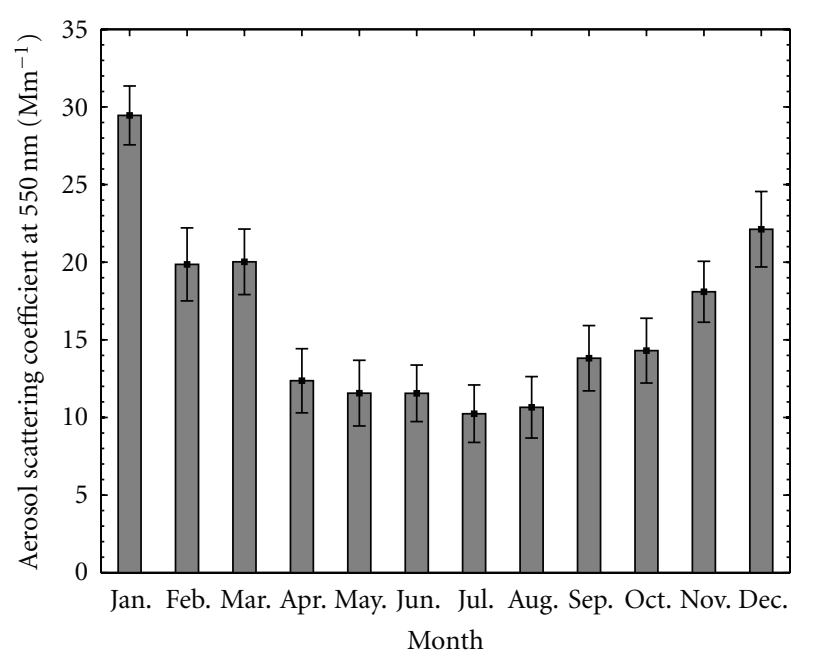

Scattering geometric mean

FIGURE 1: Seasonal variation of the $\sigma_{\text {scat }}$ (geometric mean) averaged over a period of 10 years from June, 2001 to December, 2010. The error bars represent the geometric standard deviation of the data.

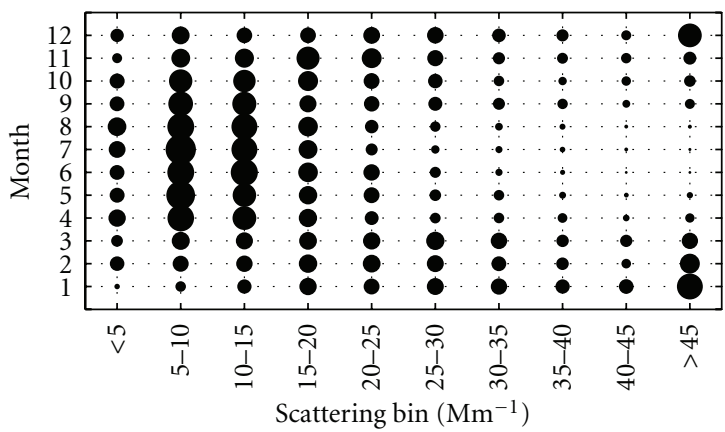

Percentage occurrence:

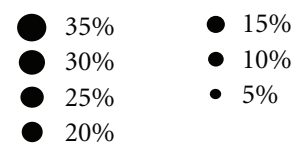

FIgURe 2: Percentage occurrence of $\sigma_{\text {scat }}$ values in different scattering bins normalized over a month.

otherwise might have been masked by a sea salt scattering signal.

We calculated the $\AA$ values using the $450 \mathrm{~nm}$ and the $700 \mathrm{~nm}$ wavelength scattering coefficient in order to extract more information from the 10 -year-long aerosol light scattering coefficient database. The $\AA$ values give information about the average size distribution of the particles. $\AA$ is extracted using the aerosol optical depth (AOD) but it is equally informative when accessed using the $\sigma_{\text {scat }}[29,30]$. We sorted the percentage occurrence of the $\sigma_{\text {scat }}$ values of each month into scattering bins with a bin width of $5 \mathrm{Mm}^{-1}$ except for the 1st and the last bins which were $<5 \mathrm{Mm}^{-1}$ and $>45 \mathrm{Mm}^{-1}$, respectively. Figure 2 shows the distribution of percentage occurrence of $\sigma_{\text {scat }}$ in scattering bins for all the months. Size of the circles in the Figure is directly

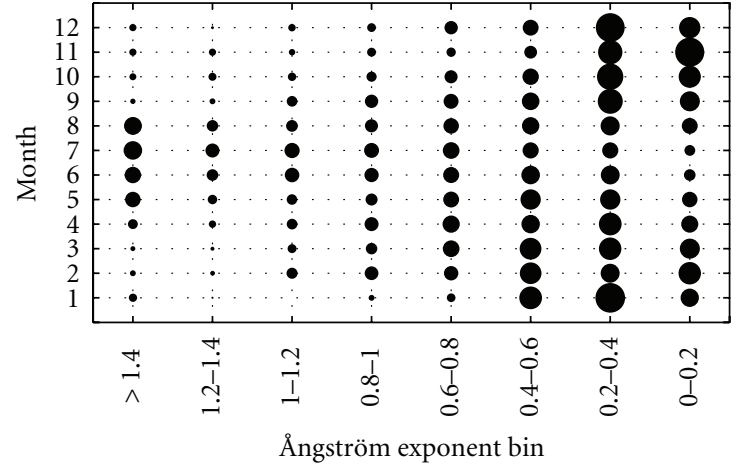

Percentage occurrence:

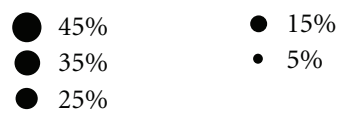

FIGURE 3: Percentage occurrence of $\AA$ values in different Ångström bins normalized over a month. Note: the Ångström bin axis is reversed in scale.

proportional to the percentage occurrence of the scattering values that is, the larger the circle represents a more frequent occurrence of scattering values in that particular bin for the month and vice versa. Similarly the frequency of occurrence of the $\AA$ values for each month was binned into $\AA$ bins of bin width 0.2 except for the last bin which was $>1.4$. The distribution of the percentage occurrence of the $\AA$ values in $\AA$ bins for all the months is shown in Figure 3. We grouped the percentage occurrence of the $\sigma_{\text {scat }}$ from $5-15 \mathrm{Mm}^{-1}$ and $>40 \mathrm{Mm}^{-1}$ and labelled them as small and large scattering values, respectively. Likewise, we grouped the percentage occurrence of the $\AA$ values into two categories, the super$\mu \mathrm{m}$ and the sub- $\mu \mathrm{m} \AA$ values, with values $0.0-0.4$ and $>1.2$, respectively. This classification of percentage occurrence of the $\AA$ values into the super- $\mu \mathrm{m}$ and the sub- $\mu \mathrm{m}$ category may not purely represent the aerosol size associated by the term but are dominated by the respective size in the said category.

A distinctive frequency pattern is observed in Figures 2 and 3 with a frequency of occurrence of the relatively larger $\sigma_{\text {scat }}$ values and relatively smaller $\AA$ values higher in the winter months. From Table 1 we find that the frequency of occurrence of large $\sigma_{\text {scat }}$ values $\left(>40 \mathrm{Mm}^{-1}\right)$ is highest for the month of January $(34.8 \%)$ as compared to other months, and it gradually decreases to $<1 \%$ for the month of July. It is evident from Figure 3 that winter months have relatively low $\AA$ values, and as we move to higher $\AA$ bins (smaller particle size) the percentage occurrence of $\AA$ is reducing. For the month of January, $63.5 \%$ of the particles have an $\AA$ value between 0.0 and 0.4 whereas particles with an $\AA$ value $>1.2$ are $<4 \%$. $\AA$ values of $<0.5$ indicate the presence of super- $\mu \mathrm{m}$ mode sea salt particles in the clean marine environment [30]. A positive correlation coefficient of 0.66 exists between the percentage occurrence of smaller $\AA$ values $(0.0-0.4)$ and the percentage occurrence of large $\sigma_{\text {scat }}$ values $\left(>40 \mathrm{Mm}^{-1}\right)$ thus confirming that high $\sigma_{\text {scat }}$ values are due to super- $\mu \mathrm{m}$ mode particles.

To study the effect of wind speed on $\sigma_{\text {scat }}$ and $\AA$, we averaged the $\sigma_{\text {scat }}$, the $\AA$, and the wind speed values into 
Table 1: Percentage occurrence of monthly $\sigma_{\text {scat }}$ and Ångström values over a period from June, 2001 to December, 2010.

\begin{tabular}{|c|c|c|c|c|}
\hline \multirow{2}{*}{ Month } & \multicolumn{2}{|c|}{$\sigma_{\text {scat }}$} & \multicolumn{2}{|l|}{$\AA$} \\
\hline & $\begin{array}{c}\text { Small } \\
\left(5-15 \mathrm{Mm}^{-1}\right)\end{array}$ & $\begin{array}{c}\text { Large } \\
\left(>40 \mathrm{Mm}^{-1}\right)\end{array}$ & $\begin{array}{c}\text { Super- } \mu \mathrm{m} \\
(0.0-0.4)\end{array}$ & $\begin{array}{c}\text { Sub- } \mu \mathrm{m} \\
(>1.2)\end{array}$ \\
\hline Jan. & 13 & 35 & 64 & 4 \\
\hline Feb. & 21 & 19 & 45 & 3 \\
\hline Mar. & 24 & 16 & 47 & 2 \\
\hline Apr. & 50 & 5 & 42 & 8 \\
\hline May. & 54 & 3 & 34 & 17 \\
\hline Jun. & 57 & 1 & 26 & 21 \\
\hline Jul. & 62 & 1 & 20 & 28 \\
\hline Aug. & 55 & 1 & 32 & 24 \\
\hline Sep. & 46 & 6 & 53 & 3 \\
\hline Oct. & 41 & 9 & 62 & 6 \\
\hline Nov. & 28 & 11 & 75 & 6 \\
\hline Dec. & 22 & 26 & 67 & 3 \\
\hline
\end{tabular}

monthly averages over a period of 10 years. Figure 4 (a) shows the seasonal variation of the $\sigma_{\text {scat }}$ (circle) and the wind speed (square), and Figure 4(b) shows the seasonal variation of the $\AA$ (circle) and the wind speed (square). The standard deviation associated with each datapoint is plotted as a dashed vertical bar for the $\sigma_{\text {scat }}$ and the $\AA$ and as a solid vertical bar for the wind speed. The large standard deviation associated with winter months $\sigma_{\text {scat }}$ is due to frequent gust wind episodes and dependence of aerosol properties on air mass history $[15,31]$. During the summer months the weather system is less active and the air mass movement is less vigorous in the North Atlantic [15], hence the variability in $\sigma_{\text {scat }}$ is less.

A high positive correlation coefficient of 0.88 exists between $\sigma_{\text {scat }}$ and wind speed thus supporting the fact that high $\sigma_{\text {scat }}$ values during the winter months are due to enhanced sea salt production which in turn is due to higher wind speed. During the summer months when the wind speed is lower, $\sigma_{\text {scat }}$ values subside. A negative correlation coefficient of -0.89 between $\AA$ and wind speed further indicates that dominance of super- $\mu \mathrm{m}$ particles during the winter months are due to higher wind speed. The increased percentage occurrence of lower $\sigma_{\text {scat }}\left(5-15 \mathrm{Mm}^{-1}\right)$ values during the summer months is not necessarily due to lower wind speeds. During the summer months, enhancement in the number concentration of sub- $\mu \mathrm{m}$ aerosol particles [11] and enhanced contribution of organics and nss sulphate to the sub- $\mu \mathrm{m}$ aerosol mass $[10,11]$ is not entirely due to lower wind speed but also due to other climatologically relevant factors (e.g., solar radiation, temperature, etc.). Higher $\AA$ values during the summer months may be due to enhanced contribution of organics to the sub- $\mu \mathrm{m}$ aerosol mass [10] which tend to affect the physicochemical properties of sea water and hence the production mechanism of wind speeddependent sea salt. The sea surface temperature might also play a crucial role in the production mechanism of wind speed-dependent production of sea salt [32].

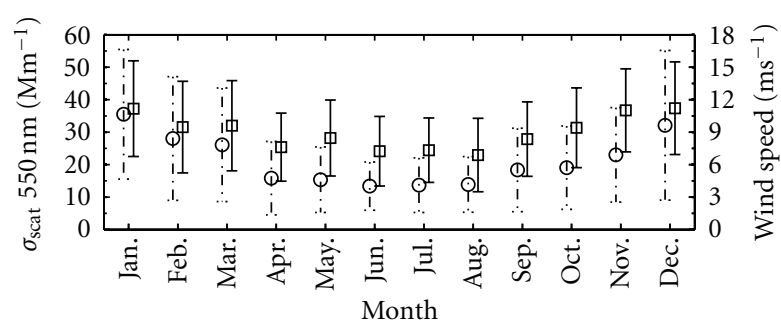

(a)

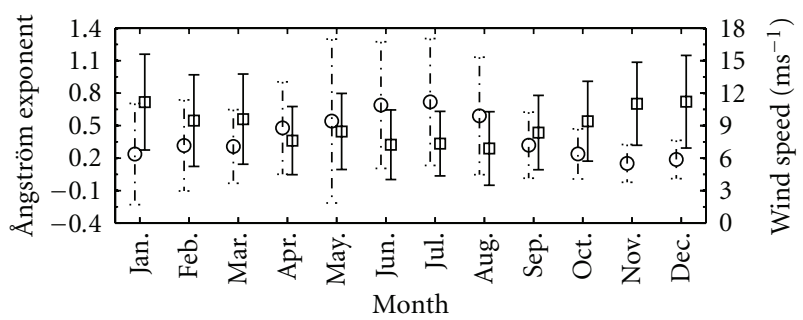

(b)

FIGURE 4: Seasonal variation of the (a) $\sigma_{\text {scat }}$ (circle) and wind speed (square), (b) $\AA$ (circle) and wind speed (square). The standard deviation associated with each datapoint is plotted as a dashed vertical bar for the $\sigma_{\text {scat }}$ and the $\AA$ and as a solid vertical bar for the wind speed. $\sigma_{\text {scat }}, \AA$, and wind speed are averaged over a period of 10 years from June, 2001 to December, 2010.

The frequency of occurrence of smaller $\sigma_{\text {scat }}$ values (5$15 \mathrm{Mm}^{-1}$ ) and larger $\AA$ values $(>1.2)$ are higher for the summer months. They are also highly correlated with a positive correlation coefficient of 0.82 . In the summer months when the movement of air masses is less vigorous, and the wind speed is low, a decrease in frequency of occurrence of smaller $\AA$ values (0.0-0.4; super- $\mu \mathrm{m}$ particles) from $63.5 \%$ (in January) to $19.7 \%$ (in July) is understandable. At the same time, an increase in frequency of occurrence of larger $\AA$ values ( $>1.2$; sub- $\mu \mathrm{m}$ particles) from $<4 \%$ (in January) to nearly $28.3 \%$ (in July) is puzzling. This accounts for nearly a 5 -fold increase in frequency of occurrence (from $12.5 \%$ in January to $62.3 \%$ in July) of $\sigma_{\text {scat }}$ values in the smaller scattering bin $\left(5-15 \mathrm{Mm}^{-1}\right)$. This significant increase cannot be explained by the sea salt-dependent scattering as the super- $\mu \mathrm{m}$ particle mode shows a decreasing trend from winter to summer. Summer in the North Atlantic waters is characterized by high biological activity and enhanced contribution of organics to the sub- $\mu \mathrm{m}$ mass of marine aerosols [10]. Also, the sub- $\mu \mathrm{m}$ nss sulphate concentration peaks in the summer months and shows a maximum for the month of July [11]. This indicates the contribution of nss-sulphate and organics towards enhanced scattering in the lower scattering bins during the summer months. This finding has significant importance as it indicates a direct link between elevated levels of the percentage occurrence of scattering in lower scattering bins and enhanced contribution of organics (up to $63 \%)$ to the sub- $\mu \mathrm{m}$ aerosol mass $[10,12]$. Enhancement of organics in the sub- $\mu \mathrm{m}$ aerosol mass will change the refractive index of the aerosol particles and hence their radiative properties. Also the enhanced fraction of organics will alter the hygroscopic properties of the aerosol particles. 
This will have an impact on the net radiative forcing over the region. In clear marine air at higher wind speeds (during the winter season) sea salt can account for up to $75 \%$ of particles above $50 \mathrm{~nm}$ and hence is a predominant source of cloud condensation nuclei (CCN) [9]. Water-soluble organic carbon (WSOC) when internally mixed with sulphate and sea salt aerosol can enhance the cloud droplet number concentration (CDNC) by 15-20\% over an updraught range of $0.1-3 \mathrm{~ms}^{-1}$. CDNC can increase from about $29 \%$ at $1 \mathrm{~ms}^{-1}$ to more than $100 \%$ at $3 \mathrm{~ms}^{-1}$, when the aerosol population is externally mixed [10]. Further research is required to study the effect of enhanced organic fraction on cloud properties. Present climate models should take into account the organic contribution to aerosol population and their effect on cloud properties.

\section{Conclusions}

Aerosol light scattering properties were measured over a period of ten years, from June 2001 to December 2010, at the Mace Head Atmospheric Research Station on the west coast of Ireland. A seasonal cycle in the $\sigma_{\text {scat }}$ has been observed over the North-East Atlantic. The month of January has the highest $\sigma_{\text {scat }}$ value of $35.3 \pm 20.0 \mathrm{Mm}^{-1}$ and the month of July has the lowest scattering coefficient value of 13.7 $\pm 8.4 \mathrm{Mm}^{-1}$. The seasonal cycle observed in the $\sigma_{\text {scat }}$ is mainly driven by the contribution of wind speed-generated sea salt (super- $\mu$ m mode) particles in the marine boundary layer during the winter season. A gradual reduction in the percentage occurrence of larger $\sigma_{\text {scat }}$ values $\left(>40 \mathrm{Mm}^{-1}\right)$ and an increase in percentage occurrence of smaller $\sigma_{\text {scat }}$ values $\left(5-15 \mathrm{Mm}^{-1}\right)$ from January to July indicate sources other than sea salt to be present during the summer months. This is confirmed by a 7 -fold increase in the percentage occurrence of larger $\AA$ values $(>1.2)$ and a high positive correlation coefficient of 0.82 between percentage occurrence of larger $\AA$ values $(>1.2)$ and percentage occurrence of a smaller $\sigma_{\text {scat }}$ values. This also indicates a contribution of nss sulphate and organics to the aerosol scattering signal as these species show an enhanced concentration during the summer months. A high positive correlation coefficient of 0.88 exists between $\sigma_{\text {scat }}$ and wind speed thus supporting our suggestion that higher winds are driving higher scattering during the winter months. $\AA$ and wind speed have a negative correlation coefficient of -0.89 . These findings are important as they are extracted from a 10-year-long aerosol database. Further work is required to better understand the role of enhanced organic matter in the sub- $\mu \mathrm{m}$ aerosol mass fraction and their effects on aerosol physicochemical and radiative properties.

\section{Acknowledgments}

The work described in this paper was supported by the EU FP6 Integrated Infrastructures Initiatives (I3) Project EUSAAR (European Supersites for Atmospheric Aerosol Research, Project FP6-026140). The authors also acknowledge the support of the European Commission through the GEOmon (Global Earth Observation and Monitoring)
Integrated Project under the 6th Framework Programme (contract Number FP6-2005-Global-4-036677).

\section{References}

[1] Intergovernmental Panel on Climate Change, Climate Change 2007: The Scientific Basis. Contribution of Working Group I to the Fourth Assessment Report of the Intergovernmental Panel on Climate Change, edited by S. Solomon et al., Cambridge University Press, Cambridge, UK, 2007.

[2] B. A. Bodhaine and E. G. Dutton, "A long term decrease in Arctic haze at Barrow, Alaska," Geophysical Research Letters, vol. 20, no. 10, pp. 947-950, 1993.

[3] B. A. Bodhaine, "Aerosol measurements during the Mauna Loa Photochemistry Experiment 2," Journal of Geophysical Research D, vol. 101, no. 9, pp. 14757-14765, 1996.

[4] K. Parameswaran, R. Rajan, G. Vijayakumar et al., "Seasonal and long term variations of aerosol content in the atmospheric mixing region at a tropical station on the Arabian sea-coast," Journal of Atmospheric and Solar-Terrestrial Physics, vol. 60, no. 1, pp. 17-25, 1998.

[5] M. Collaud Coen, E. Weingartner, S. Nyeki et al., "Longterm trend analysis of aerosol variables at the high-alpine site Jungfraujoch," Journal of Geophysical Research D, vol. 112, no. 13, Article ID D13213, 2007.

[6] S. N. Pereira, F. Wagner, and A. M. Silva, "Seven years of measurements of aerosol scattering properties, near the surface, in the southwestern Iberia Peninsula," Atmospheric Chemistry and Physics, vol. 11, no. 1, pp. 17-29, 2011.

[7] N. C. Ahlquist and R. J. Charlson, "Measurement of the wavelength dependence of atmospheric extinction due to scatter," Atmospheric Environment, vol. 3, no. 5, pp. 551-564, 1969.

[8] S. G. Jennings and C. D. O'Dowd, "Volatility of aerosol at Mace Head, on the west coast of Ireland," Journal of Geophysical Research, vol. 95, no. 9, pp. 13937-13948, 1990.

[9] C. D. O’Dowd and M. H. Smith, "Physicochemical properties of aerosols over the northeast Atlantic: evidence for windspeed-related submicron sea-salt aerosol production," Journal of Geophysical Research, vol. 98, no. 1, pp. 1137-1149, 1993.

[10] C. D. O'Dowd, M. C. Facchini, F. Cavalli et al., "Biogenically driven organic contribution to marine aerosol," Nature, vol. 431, no. 7009, pp. 676-680, 2004.

[11] Y. J. Yoon, D. Ceburnis, F. Cavalli et al., "Seasonal characteristics of the physicochemical properties of North Atlantic marine atmospheric aerosols," Journal of Geophysical Research D, vol. 112, no. 4, Article ID D04206, 2007.

[12] J. Ovadnevaite, C. O’Dowd, M. Dall'Osto, D. Ceburnis, D. R. Worsnop, and H. Berresheim, "Detecting high contributions of primary organic matter to marine aerosol: a case study," Geophysical Research Letters, vol. 38, no. 2, p. L02807, 2011.

[13] T. C. O'Connor, S. G. Jennings, and C. D. O’Dowd, "Highlights of fifty years of atmospheric aerosol research at Mace Head," Atmospheric Research, vol. 90, no. 2-4, pp. 338-355, 2008.

[14] M. Dall'Osto, D. Ceburnis, G. Martucci et al., "Aerosol properties associated with air masses arriving into the North East Atlantic during the 2008 Mace Head EUCAARI intensive observing period: an overview," Atmospheric Chemistry and Physics, vol. 10, no. 17, pp. 8413-8435, 2010.

[15] S. G. Jennings, C. Kleefeld, C. D. O’Dowd et al., "Mace Head Atmospheric Research Station-characterization of aerosol radiative parameters," Boreal Environment Research, vol. 8, no. 4, pp. 303-314, 2003. 
[16] J. P. Mulcahy, C. D. O'Dowd, S. G. Jennings, and D. Ceburnis, "Significant enhancement of aerosol optical depth in marine air under high wind conditions," Geophysical Research Letters, vol. 35, no. 16, Article ID L16810, 2008.

[17] T. L. Anderson, D. S. Covert, S. F. Marshall et al., "Performance characteristics of a high-sensitivity, three-wavelength, total scatter/backscatter nephelometer," Journal of Atmospheric and Oceanic Technology, vol. 13, no. 5, pp. 967-986, 1996.

[18] T. L. Anderson and J. A. Ogren, "Determining aerosol radiative properties using the TSI 3563 integrating nephelometer," Aerosol Science and Technology, vol. 29, no. 1, pp. 57-69, 1998.

[19] J. Heintzenberg and R. J. Charlson, "Design and applications of the integrating nephelometer: a review," Journal of Atmospheric and Oceanic Technology, vol. 13, no. 5, pp. 987-1000, 1996.

[20] C. Kleefeld, C. D. O’Dowd, S. O’Reilly et al., "Relative contribution of submicron and supermicron particles to aerosol light scattering in the marine boundary layer," Journal of Geophysical Research D, vol. 107, no. 19, article 8103, 2002.

[21] A. D. A. Hansen, H. Rosen, and T. Novakov, "Real-time measurement of the absorption coefficient of aerosol particles," Applied Optics, vol. 21, no. 17, pp. 3060-3062, 1982.

[22] A. D. A. Hansen, H. Rosen, and T. Novakov, "The aethalometer - an instrument for the real-time measurement of optical absorption by aerosol particles," Science of the Total Environment, vol. 36, pp. 191-196, 1984.

[23] W. F. Cooke, S. G. Jennings, and T. G. Spain, "Black carbon measurements at Mace Head, 1989-1996," Journal of Geophysical Research D, vol. 102, no. 21, pp. 25339-25346, 1997.

[24] D. S. Covert, R. J. Charlson, and N. C. Ahlquist, "A Study of the Relationship of Chemical Composition and Humidity to Light Scattering by Aerosols," Journal of Applied Meteorology, vol. 11, no. 6, pp. 968-976, 1972.

[25] I. N. Tang, "Phase transformation and growth of aerosol particles composed of mixed salts," Journal of Aerosol Science, vol. 7, no. 5, pp. 361-371, 1976.

[26] I. N. Tang, "Chemical and size effects of hygroscopic aerosols on light scattering coefficients," Journal of Geophysical Research D, vol. 101, no. 14, pp. 19245-19250, 1996.

[27] R. Fierz-Schmidhauser, P. Zieger, A. Vaishya et al., "Light scattering enhancement factors in the marine boundary layer (Mace Head, Ireland)," Journal of Geophysical Research D, vol. 115, no. 20, Article ID D20204, 2010.

[28] C. D. O’Dowd, M. H. Smith, I. E. Consterdine, and J. A. Lowe, "Marine aerosol, sea-salt, and the marine sulphur cycle: a short review," Atmospheric Environment, vol. 31, no. 1, pp. 73-80, 1997.

[29] E. Öström and K. J. Noone, "Vertical profiles of aerosol scattering and absorption measured in situ during the North Atlantic Aerosol Characterization Experiment (ACE-2)," Tellus B, vol. 52, no. 2, pp. 526-545, 2000.

[30] A. Smirnov, B. N. Holben, Y. J. Kaufman et al., "Optical properties of atmospheric aerosol in maritime environments," Journal of the Atmospheric Sciences, vol. 59, no. 3, part 1, pp. 501-523, 2002.

[31] S. G. Jennings, M. Geever, F. M. McGovern, J. Francis, T. G. Spain, and T. Donaghy, "Microphysical and physicochemical characterization of atmospheric marine and continental aerosol at Mace Head," Atmospheric Environment, vol. 31, no. 17, pp. 2795-2808, 1997.

[32] C. D. O’Dowd and G. De Leeuw, "Marine aerosol production: a review of the current knowledge," Philosophical Transactions of the Royal Society A, vol. 365, no. 1856, pp. 1753-1774, 2007. 

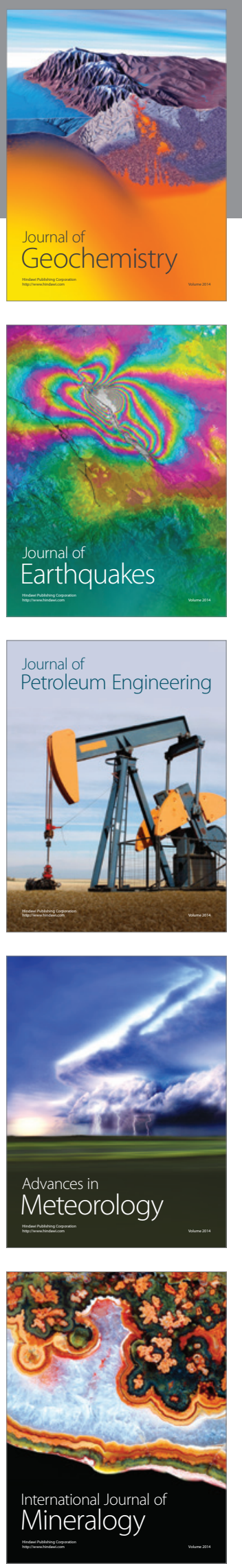
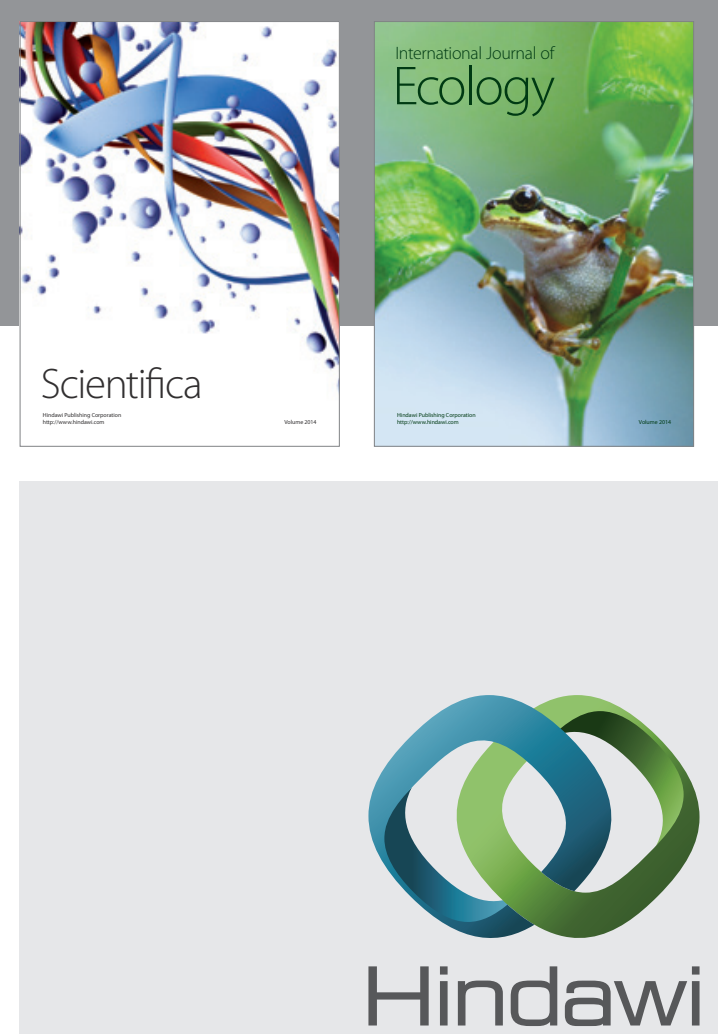

Submit your manuscripts at http://www.hindawi.com
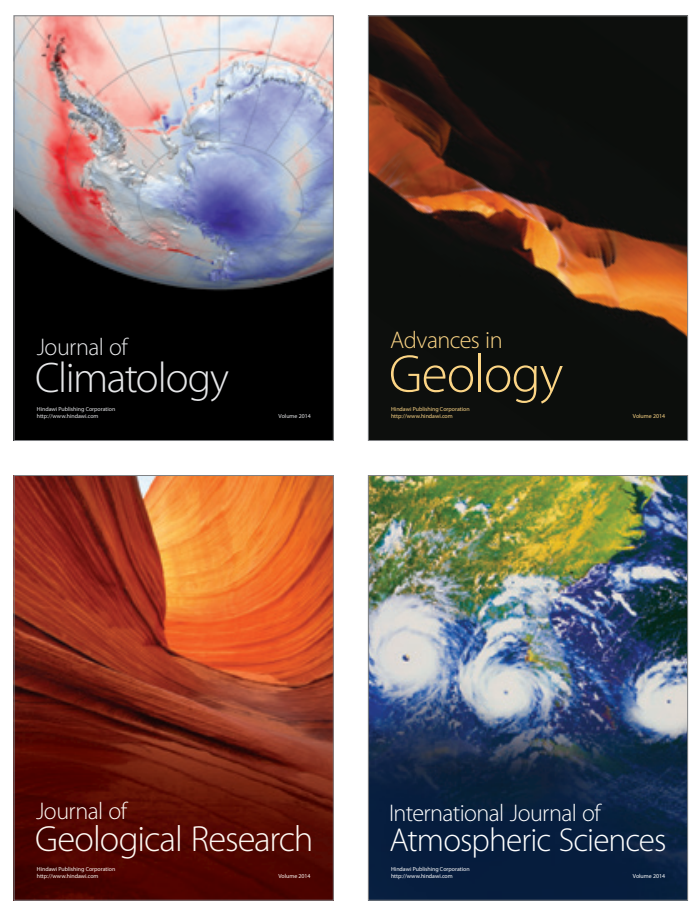
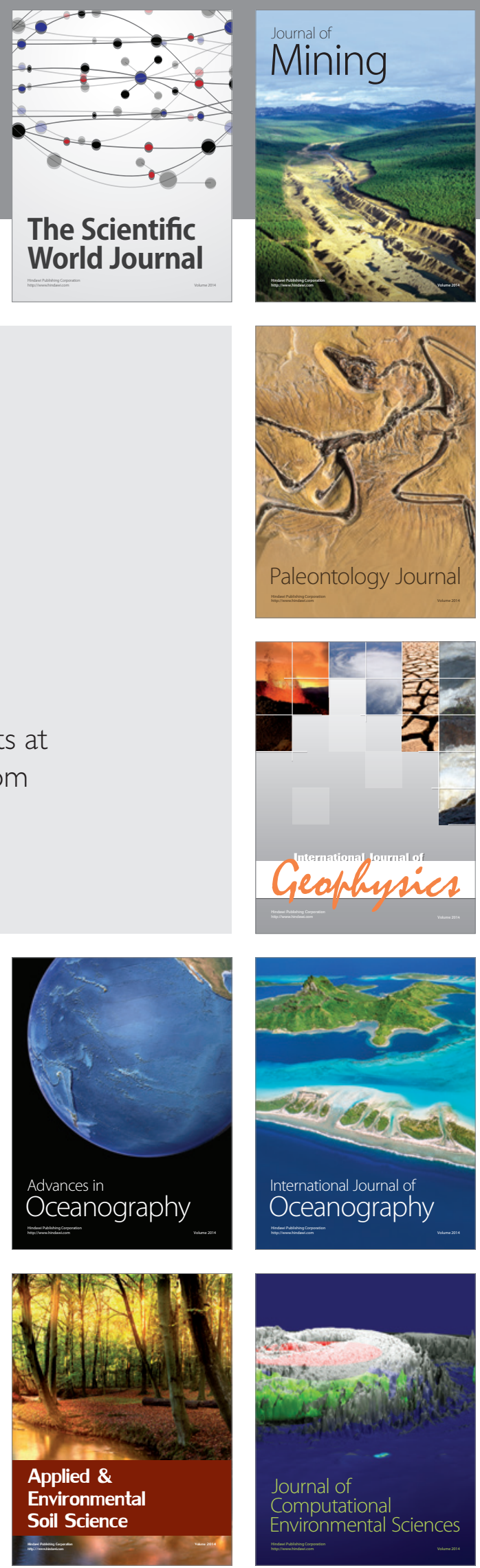